Letter to the Editor

\title{
Rabies in Asian Countries: Where we are stand?
}

\author{
Tauseef Ahmad*, Taha Hussein Musa, Hui Jin*
}

Key Laboratory of Environmental Medicine Engineering, Ministry of Education, Department of Epidemiology and Health Statistics, School of Public Health, Southeast University, Nanjing 210009, Jiangsu, China

Correspondence

Tauseef Ahmad, Key Laboratory of Environmental Medicine Engineering, Ministry of Education, Department of Epidemiology and Health Statistics, School of Public Health, Southeast University, Nanjing 210009, Jiangsu, China

Email:

hamdardmicrobiologist@gmail.com

Correspondence

Hui Jin, Key Laboratory of

Environmental Medicine Engineering Ministry of Education, Department of Epidemiology and Health Statistics, School of Public Health, Southeast University, Nanjing 210009, Jiangsu, China

Email: jinhui_hld@163.com

History

- Received: 24 September 2018

- Accepted: 05 October 2018

- Published: 12 October 2018

DOI :

https://doi.org/10.15419/bmrat.v5i10.485

\section{Check for updates}

\section{Copyright}

(c) Biomedpress. This is an openaccess article distributed under the terms of the Creative Commons Attribution 4.0 International license.

ABSTRACT

Rabies is one of the neglected zoonotic disease in Asian and African countries. This article highlights the rabies death rate in Asian countries during 2010-2014. High death rate was reported in China, Philippine and Vietnam. The overall death rate has dropped since 2010 to 2014 but still the disease is prevalent in some Asian countries. Reinforcement of the rabies surveillance is needed to strengthened national, regional and global reporting system to control and eliminate the disease by 2030 .

Key words: Asian countries, Death rate, Rabies

\section{INTRODUCTION}

\section{Dear Sir}

Rabies is one of the neglected zoonotic and fully vaccine preventable viral disease with an approaching $(100 \%)$ case fatality rate ${ }^{1}$. The disease mainly transmitted by the bite of rabies infected dog accounts for (99\%) cases. Globally, each year approximately 59,000 individuals died from dog-mediated rabies. In Asia, due to dog-mediated rabies an estimated 35,172 human deaths (59.6\% of global deaths) occurred per year, while in Africa, an estimated 21,476 human rabies deaths (36.4\% of global deaths) reported per year. In Asia, India is the leading county accounts for the most human rabies deaths (59.9\%) and globally $(35 \%)^{2}$. After India, China is another country that experience most serious impact from rabies, among the list of 39 notifiable infectious diseases in the country, deaths due to rabies ranked third ${ }^{3}$.

However, after a huge economic investment rabies is still a significant major health problem in Asian and African countries. Some of the published studies reported that about the adequate prophylactic steps following dog bites rabies cases surprisingly the physicians have insufficient knowledge $e^{4,5}$. In many parts of the world, rabies human deaths are significantly unreported $^{2}$.

This study was conducted to explore the total number of deaths per year from dog-transmitted rabies in Asian countries for the period 2010 to 2014. The data extracted from the World Health Organization (WHO) website. For many Asian countries, the data are not available or incomplete data on the WHO website so therefore excluded from the analysis. The number of deaths cases was calculated in clinically diagnosed and laboratory confirmed cases as per the country reporting system ${ }^{6}$.

Table 1 showed the reported human rabies deaths. Maximum number of rabies deaths were reported from China, Philippines and Vietnam. However, the overall rabies deaths have dropped since 2010 to 2014 . As per our findings the deaths rate is decreased but it was only among the clinically diagnosed or laboratory confirmed cases. However, many deaths from rabies remain unreported especially occurred in the community. Anyhow, it is forward moving towards rabies control and elimination by 2030 .

Another fact, that for some of the large Asian countries (i.e. India, Pakistan and Bangladesh) the data are not available. So therefore, it is hard to say either in community set up the rabies death rate decreases or not? Therefore, further studies are recommended to report the exact epidemiological data of rabies in community set up. Still many developing countries faces challenges during the identification, diagnosis and reporting of rabies cases due to lack of public awareness, poor surveillance, laboratory facilities, shortage of skilled health-care workers, absence of proper coordination among all the sector involved. Effective rabies control programmes, better surveillance, strengthened national, regional and global reporting system especially in the Asian and African countries are necessary. Many Pacific island nation and Australia are dog-mediated rabies free regions but still report the imported cases of rabies, which is one of the best example for the rabies prevalent countries. 
Table 1: Reported number of human rabies deaths by selected Asian countries from 2010-2014

\begin{tabular}{clccccc}
\hline S. No. & Country/Year & $\mathbf{2 0 1 0}$ & $\mathbf{2 0 1 1}$ & $\mathbf{2 0 1 2}$ & $\mathbf{2 0 1 3}$ & $\mathbf{2 0 1 4}$ \\
1 & China & 2014 & 1879 & 1361 & 1128 & 854 \\
2 & Georgia & 1 & 1 & 2 & 4 & 2 \\
3 & Iran & 4 & 8 & 6 & 5 & 4 \\
4 & Kyrgyzstan & 3 & 4 & 0 & 1 & $\mathrm{~d}$ \\
5 & Philippines & 299 & 229 & 213 & 205 & 236 \\
6 & Sri Lanka & 49 & 41 & 38 & 28 & 19 \\
7 & Syria & 1 & 2 & 5 & 7 & 0 \\
8 & Thailand & 15 & 8 & 5 & 5 & 5 \\
9 & Turkey & 0 & 2 & 1 & 2 & $\mathrm{~d}$ \\
10 & Vietnam & 87 & 110 & 98 & 105 & 67 \\
11 & Total & 2473 & 2284 & 1729 & 1490 & 1187 \\
\hline
\end{tabular}

Note. $\mathrm{d}=$ data not available.

\section{This article highlights the rabies death rate in Asian countries. \\ This article may convey an important message to reinforce the rabies surveillance, preventive measurements and vaccination campaign in those countries where the rabies is prevalent.}

\section{Highlights}

\section{CONFLICT OF INTEREST}

The author(s) declared no conflicts of interest.

\section{FINANCIAL SUPPORT}

The author(s) received no financial support.

\section{AUTHORS CONTRIBUTION}

Idea and study designed: TA

Acquisition of data: TA, THA
Analysis and interpretation of data: TA, THA

Drafting of manuscript: TA

Study supervised: $\mathrm{HJ}$

\section{REFERENCES}

1. Baghi HB, Bazmani A, Aghazadeh M. The fight against rabies: the Middle East needs to step up its game. Lancet. 2016;388:1880. Available from: Doi:10.1016/s0140-6736(16) 31729-9.

2. WHO. WHO expert consultation on rabies: third report; 2018 . null. Available from: http://apps.who.int/iris.

3. Qi L, Su K, Shen T, Tang W, Xiao B, Long J. Epidemiological characteristics and post-exposure prophylaxis of human rabies in Chongqing, China, 2007-2016. BMC Infectious Diseases. 2018;18:6. Available from: DOI:10.1186/s12879-017-2830-x.

4. Chowdhury R, Mukherjee A, Naskar S, Lahiri SK. A study on knowledge of animal bite management and rabies immunization among interns of a government medical college in Kolkata. International Journal of Medicine and Public Health. 2013:3:1720. Available from: Doi:10.4103/2230-8598.109313.

5. Vashishtha VM, Choudhury P, Kalra A, Bose A, Thacker N, Yewale $\mathrm{VN}$, et al. Indian Academy of Pediatrics (IAP) recommended immunization schedule for children aged 0 through 18 yearsIndia, 2014 and updates on immunization. Indian Pediatrics. 2014;51:785-800. Available from: DOI:10.1007/s13312-0140504-y.

6. WHO. Global Health Observatory visualizations, Reported number of human rabies deaths Data by country; 2016. Available from: node.main.NTDRABIESHUMANDEATHS. 